\title{
Redes de promoção de atividade física: uma reflexão entre discurso e a prática
}

Douglas Roque Andrade 1,2, Erinaldo Luiz de Andrade ${ }^{3,4}$, Leandro Martin Totaro Garcia,

A conformação de redes setoriais e intersetoriais é considerada uma das estratégias necessárias e efetivas para o sucesso da promoção da atividade física ${ }^{1-3}$. De fato, é difícil encontrar algum ator envolvido na promoção da atividade física que não reconheça a importância de se organizar e atuar em rede. No entanto, em geral, a prática não acompanha o discurso.

No setor industrial, o valor desse tipo de organização está amplamente reconhecido e vem sendo largamente aplicado. Por exemplo, a ONG Oxfam International elaborou, em 2014, um infográfico demonstrando as 10 companhias que controlam quase todo o mercado de alimentos e bebidas industrializados ${ }^{4}$. Nesse infográfico estão as principais companhias, conectadas a diversas marcas, que dedicam uma intrincada infraestrutura de recursos humanos, materiais, informacionais e financeiros para produzir, distribuir, vender e lucrar, despertando o nosso desejo em iniciar ou manter o consumo de seus produtos em escala global, com estratégias centradas no comportamento humano. Essas companhias possuem diferentes departamentos, como logística, marketing, publicidade, vendas, financeiro, desenvolvimento, inovação e recursos humanos, reunindo profissionais de diversas áreas trabalhando em rede para atingir metas comuns.

Enquanto isso, na área, pesquisadores, docentes e profissionais de saúde, com muito esforço se reúnem com os pares. Na prática, o que se tem visto é que redes foram criadas e estão em desenvolvimento, como a própria rede da Sociedade Brasileira de Atividade Física e Saúde, a Rede Agita Mundo e a rede da Sociedade Internacional de Atividade Física e Saúde, entre outras. Porém, todas apresentam alto grau de similitude entre seus atores - são redes homofílicas, pouco heterogêneas. É crônica e histórica a falta de interação e vínculos entre as diversas áreas que se debruçam sobre o fenômeno atividade física a partir de perspectivas distintas, assim como sobre outras temáticas da Educação Física. Ademais, o investimento humano, financeiro, em tempo e conhecimento dedicado à formação, evolução e manutenção de redes, por parte de todos os envolvidos, ainda é aquém do necessário para que se possa usufruir de todo o potencial desse tipo de organização.

Acredita-se que para promover a atividade física, além de continuar a produzir conhecimento, é preciso formar uma rede bem conectada, composta de distintos grupos e capaz de ampliar, difundir e aplicar os recursos materiais e imateriais que gera e compartilha, além de responder e se adaptar mais rápida e adequadamente

1 Universidade de São Paulo, Escola de Artes Ciências e Humanidades, Programa de Pós-Graduação em Ciências da Atividade Física. São Paulo, SP, Brasil.

2 Universidade de São Paulo, Grupo de Estudos e Pesquisas Epidemiológicas em Atividade Física e Saúde. São Paulo, SP, Brasil.

3 Universidade Nove de Julho. São Paulo, SP, Brasil.

4 Universidade São Judas Tadeu, Programa de Pós-Graduação em Educação Física. São Paulo, SP, Brasil.

5 Fundação Oswaldo Cruz, Programa de Pós-Graduação em Epidemiologia em Saúde Pública. Rio de Janeiro, RJ, Brasil. 
às demandas e desafios que a sociedade apresenta. Esse esforço necessita de infraestrutura, processos, papeis e conhecimentos que suportem a rede e facilitem o engajamento dos seus atores. No entanto, essa estrutura não precisa estar concentrada ou depender de poucas fontes, mas pode estar distribuída pelos atores que compõem a rede, em uma organização colaborativa e horizontal.

Para começar, são necessários a aproximação e o engajamento de distintos setores e atores interessados ou envolvidos na promoção da atividade física. Entre eles, devem estar a sociedade civil e coletivos da sociedade, profissionais e instituições formadoras (professores e Instituições de Ensino Superior), pesquisadores de diversas áreas, profissionais da saúde, profissionais de marketing e comunicação, gestores públicos e técnicos de secretarias governamentais, entre outros. Isso não é novidade no discurso, mas na prática, a pergunta que se precisa responder é: onde esses grupos se encontram para refletir e, principalmente, agir conjuntamente?

Um exemplo é a reunião de colegiado do Programa Agita São Paulo, que desde 1996 reúne-se com seus parceiros toda primeira terça-feira de cada mês (exceto janeiro), envolvendo representantes de vários dos grupos citados. Desde então, já foram totalizadas pelo menos 440 horas de trabalho, mais do que refletindo, agindo ${ }^{5}$.

Outro exemplo é o Sistema Único de Saúde brasileiro, que conseguiu avanços ao adotar uma rede hierarquizada como estratégia de atendimento. Porém, entre as ações da atenção básica, onde a prevenção e promoção da saúde acontecem, essa articulação ainda carece de maior esforço e investimento, inclusive de pesquisa.

Nesse sentido, a promoção da atividade física na atenção básica poderia ser potencializada se pessoas, alguma instituição ou um conjunto de atores assumisse o protagonismo necessário para iniciar essa coalização. E para começar bastaria realizar um diagnóstico sobre quais são as pessoas e instituições que promovem atividade física no território. Provavelmente encontraria o óbvio: representantes dos setores do governo (por exemplo, educação, esporte, saúde e cultura), da sociedade civil (coletivos, ONGs e Sistema S, entre outros) e Instituições de Ensino Superior. A partir desse diagnóstico, seria possível promover meios para refletir e estabelecer ações conjuntas de promoção da atividade física e de geração e fortalecimento de vínculos que permitam a todos os atores serem mais robustos e efetivos, ampliando e fortalecendo a ação de todos sobre o território.

Sem a pretensão de criar um modelo, algumas questões norteadoras poderiam servir para disparar esse processo: (1) O que já vem sendo feito para promover a atividade física?; (2) O que já se faz em parceria?; (3) O que mais pode ser feito de forma conjunta?; (4) O que pode ser feito para que todos os atores envolvidos possam crescer?; e (5) Como isso pode ser construído de forma conjunta?

Aqueles que já se engajam no trabalho em rede sabem que não é fácil, mas que é possível e gratificante. Aliás, seria de grande utilidade se suas experiências também fossem mais compartilhadas. As produções científicas disseminadas e compartilhadas por meios de revistas e sociedades científicas no país têm tido grande ênfase nos níveis de atividade e em seus fatores determinantes e associados, que geralmente não atingem os gestores e profissionais que atuam na prática. Além disso, há menos relatos de intervenções ou formas de gestão de programas (bem-sucedidos ou não), que poderiam ser compartilhados por outros atores e meios de comunicação fora da academia, contribuindo para o planejamento, execução e avaliação de estratégias de promoção da atividade física. Nesse sentido, vale destacar o espaço que esta revista oferece para esse importante tipo de relato, em sua seção especial "Do diagnóstico à ação: experiências em promoção da atividade física e saúde". 
Produzir (e consumir) ciência de alta qualidade é fundamental para o avanço da promoção da atividade física. Mas além disso, os pesquisadores precisam incluir em suas agendas tempo para se conectar aos diversos atores e instituições que promovem a atividade física. Dedicar parte do tempo ao desenvolvimento e fortalecimento em rede é estratégico para que todos que militam e atuam nessa área cumpram mais plenamente seus papeis e objetivos, inclusive os mais audaciosos.

Para saber mais sobre a formação de redes em saúde e atividade física, recomenda-se a leitura de quatro documentos:

1) O manual "Gestão de redes na OPAS/OMS Brasil: conceitos, práticas e lições aprendidas", da Organização Pan-Americana da Saúde ${ }^{6}$;

2) O capítulo "Identificação de redes de promoção da atividade", do livro "Experiência de promoção da atividade física na Estratégia de Saúde da Família”, que relata uma experiência prática de diagnóstico de uma rede local de promoção de atividade física ${ }^{7}$;

3) Um artigo de Ross Brownson e colaboradores, em que se analisa uma rede de instituições de promoção da atividade física no Brasil ${ }^{8}$;

4) O guia "Work the net", que apresenta passos para se iniciar e gerir uma rede?

\section{Contribuiç̧ão dos autores}

D. R. Andrade e E. L. Andrade conceberam as ideias iniciais do texto. D. R. Andrade, E. L. Andrade e L. M. T. Garcia se envolveram na escrita e revisão crítica do texto e aprovaram a sua versão final.

\section{Referências}

1. Bull FC, Bellew B, Schoppe S, Bauman AE. Developments in National Physical Activity Policy: an international review and recommendations towards better practice. J Sci Med Sport. 2004;7(1 Suppl.):93-104.

2. Brasil. Ministério da Saúde. Redefinição da Política Nacional de Promoção da Saúde (PNPS). Decreto no 2.446/GM/MS. Novembro 11, 2014.

3. World Health Organization. Global strategy on diet, physical activity and health. Genebra: WHO; 2004.

4. Oxfam International. These 10 companies make a lot of the food we buy. Here's how we made them better. Disponível em: https://www.oxfamamerica.org/explore/stories/these10-companies-make-a-lot-of-the-food-we-buy-heres-how-we-made-them-better/. Acesso em 10 de fevereiro de 2017.

5. Matsudo SM, Matsudo VR, Araujo TL, Andrade DR, Andrade EL, Oliveira LC et al. The Agita São Paulo Program as a model for using physical activity to promote health. Rev Panam Salud Publica. 2003; 14(4): 265-72.

6. Organização Pan-Americana da Saúde. Gestão de redes na OPAS/OMS Brasil: conceitos, práticas e lições aprendidas. Brasília: OPAS-Brasil; 2008.

7. Andrade DR, Garcia LMT, Santos LC, Bonfim GK. Identificação de redes de promoção da atividade. In: Florindo AA, Andrade DR (eds.) Experiência de promoção da atividade física na Estratégia de Saúde da Família. Curitiba: SBAFS; 2015. p. 227-41. Disponível em: http://www.each.usp.br/gepaf/livro.php. Acesso em 10 de fevereiro de 2017

8. Brownson RC, Parra DC, Dauti M, Harris JK, Hallal PC, Hoehner C, et al. Assembling the puzzle for promoting physical activity in Brazil: a social network analysis. J Phys Act Health. 2010; 7(Suppl 2):S242-52.

9. Gluek M. Work the net: a management guide for formal networks. New Delhi: GTZ; 2006.

Endereço para

correspondência

Douglas Roque Andrade

douglas.andrade@usp.br
EACH-USP. Rua Arlindo Béttio, 1000. São

Paulo, SP, Brasil. CEP: 03828-000.

Telefone: 11 99967-2182. 